\title{
Leaf Lettuce Yield Is More Sensitive to Low Daily Light Integral than Kale and Spinach
}

\author{
David A. Baumbauer \\ Department of Plant Sciences and Plant Pathology, Montana State \\ University Bozeman, MT 59717
}

Colleen B. Schmidt

Department of Ecology, Evolution and Environmental Biology, Columbia University, New York, NY 10027

\section{Macdonald H. Burgess \\ Department of Plant Sciences and Plant Pathology, Montana State University Bozeman, MT 59717}

Additional index words. cool season vegetable production, leafy greens, low light response

\begin{abstract}
Kale, leaf lettuce, and spinach were grown for 28 days in growth chambers under daily light integrals (DLI) of $8,10,12$, and $14 \mathrm{~mol} \cdot \mathrm{m}^{-2} \cdot \mathrm{d}^{-1}$. Fresh weight (FW), dry weight (DW), leaf area, and chlorophyll concentration were measured. Increasing DLI positively influenced lettuce $\mathrm{FW}$; an increase from $1.27 \mathrm{~g} / \mathrm{plant}$ to $4.33 \mathrm{~g} / \mathrm{plant}$ was measured. DW for all species increased in a linear fashion under increasing DLI, with lettuce increasing $203 \%$, kale $47 \%$, and spinach $42 \%$ as DLI increased from 8 to 14 $\mathbf{m o l} \cdot \mathrm{m}^{-2} \cdot \mathrm{d}^{-1}$. Leaf area response was species-dependent, with lettuce leaf area increasing under increasing DLI while kale leaf area decreased under higher DLI. Chlorophyll levels in kale leaves decreased from DLI of 8 to $12 \mathrm{~mol} \cdot \mathrm{m}^{-2} \cdot \mathrm{d}^{-1}$, and then increased to 14 $\mathrm{mol} \cdot \mathrm{m}^{-2} \cdot \mathrm{d}^{-1}$ DLI. Chlorophyll content in kale leaves had a nonlinear response to DLI and the best fit was with a quadratic model. Growers wanting to add supplemental lighting can expect the greatest gains in lettuce yield compared with those of kale and spinach.
\end{abstract}

Growers of leafy greens in mid-latitude $\left(40-50^{\circ}\right)$ high tunnels who wish to extend their growing season past mid-autumn are faced with two significant challenges: low air temperatures, primarily at night, and low daily light integral (DLI) due to short daylength and low sun angle and light attenuation by the plastic film high tunnel covering. For instance, Bozeman, MT (lat. $45.677^{\circ} \mathrm{N}$, long. $111.0429^{\circ} \mathrm{W}$ ), has monthly average DLI values of $11.3 \mathrm{~mol} \cdot \mathrm{m}^{-2} \cdot \mathrm{d}^{-1}$ in November, $7.6 \mathrm{~mol} \cdot \mathrm{m}^{-2} \cdot \mathrm{d}^{-1}$ in December, $8.2 \mathrm{~mol} \cdot \mathrm{m}^{-2} \cdot \mathrm{d}^{-1}$ in January, and $14.7 \mathrm{~mol} \cdot \mathrm{m}^{-2} \cdot \mathrm{d}^{-1}$ in February (Faust and Logan, 2018). Coupled with the $60 \%$ to $70 \%$ reduction in light energy at the crop level due to the high tunnel structure and plastic film covering in December and January (Biernbaum, 2013), the low DLI can limit growth even if the high tunnel air temperature is adequate. High tunnel growers have managed below-freezing air temperatures by adding heat to the air and/or soil and by using secondary row covers (Bumgarner et al., 2012; Drost et al., 2017; Hunter et al.,

\footnotetext{
Received for publication 13 June 2019. Accepted for publication 22 Sept. 2019.

Funding for this project was provided by the Montana Department of Agriculture's Specialty Crop Block grant program.

D.A.B. is the corresponding author. E-mail: baumbauer@montana.edu.
}

2012). The concept of a minimally heated high tunnel has been called the "cool greenhouse," and it has been reported that maintaining the greenhouse air temperature at $1.5^{\circ} \mathrm{C}$ resulted in twice as many harvests and allowed for a wider selection of crops during the winter months compared with unheated high tunnels (Coleman, 2009). Determining how much heat to add to a high tunnel to keep the air temperature above freezing is a relatively simple calculation (Nelson, 2012). However, the optimum amount of additional light required to maximize profits is species-specific and location-specific; therefore, it is more difficult to determine.

Plant responses to varying light intensity. Leafy greens react to low light intensity physically, by exhibiting changes in fresh and dry biomass and leaf area, and chemically, through variations in chlorophyll content and compounds both beneficial and harmful to human health. The literature reported an increase in fresh and dry biomass across cultivars with the increasing DLI. Lefsrud et al. (2006a) reported linear increases in the fresh and dry biomass of kale with DLI increases from 10.8 to 43.2 $\mathrm{mol} \cdot \mathrm{m}^{-2} \cdot \mathrm{d}^{-1}$. Gent (2016) found an increase in the DW of spinach as the DLI increased from 3 to $27 \mathrm{~mol} \cdot \mathrm{m}^{-2} \cdot \mathrm{d}^{-1}$, and Gaudreau et al. (1994) reported lettuce yield increases between $140 \%$ and $270 \%$ with a supplemental DLI of 12 to $13 \mathrm{~mol} \cdot \mathrm{m}^{-2} \cdot \mathrm{d}^{-1}$ compared with plants grown without supplemental lighting (Gaudreau et al., 1994; Gent, 2016). Research has supported both increases and decreases in leaf area with increasing DLI, depending on the cultivar. In contrast, $\mathrm{Fu}$ et al. (2017) reported that lettuce leaf area decreased when the DLI increased from 4 to $14 \mathrm{~mol} \cdot \mathrm{m}^{-2} \cdot \mathrm{d}^{-1}$. Proietti et al. (2004) found that the spinach leaf area increased under higher DLI levels, and Yao et al. (2017) found that kale grown under $13 \mathrm{~mol} \cdot \mathrm{m}^{-2} \cdot \mathrm{d}^{-1}$ produced 2.4-times more leaf area than kale grown under $8.6 \mathrm{~mol} \cdot \mathrm{m}^{-2} \cdot \mathrm{d}^{-1}$.

Chlorophyll content is closely correlated with leaf nitrogen levels, leaf area, plant size, transpiration rate, and antioxidant compounds such as anthocyanins and carotenoids (Kopsell et al., 2004; Steidle Neto et al., 2017). Literature regarding chlorophyll content variations with increasing DLI indicated that the chlorophyll response to increasing DLI is species-specific. Lefsrud et al. (2006a) found that the total chlorophyll content of kale increased as the DLI increased from 11 to $21.6 \mathrm{~mol} \cdot \mathrm{m}^{-2} \cdot \mathrm{d}^{-1}$. Conversely, $\mathrm{Fu}$ et al. (2012) found that chlorophyll-A and chlorophyll-B contents in lettuce decreased with the DLI increasing from 4 to $14 \mathrm{~mol} \cdot \mathrm{m}^{-2}$ $\cdot d^{-1}$. Yao et al. (2017) found no difference in the chlorophyll content between kale grown in $8.6 \mathrm{~mol} \cdot \mathrm{m}^{-2} \cdot \mathrm{d}^{-1}$ and kale grown in 13 $\mathrm{mol} \cdot \mathrm{m}^{-2} \cdot \mathrm{d}^{-1}$. In addition to influencing growth characteristics, low light intensities may reduce compounds beneficial to human health, such as antioxidants, and increase potentially harmful compounds, such as nitrate and oxalate (Proietti et al., 2004; Zhu et al., 2017).

By growing common, cool season leafy greens under varying low to moderate DLI values, this study aimed to determine the minimum DLI required to produce marketquality baby kale, leaf lettuce, and spinach, and to ascertain whether individual cultivars respond linearly or otherwise to the increasing DLI. Our study differed from similar light intensity effects studies because the growth chamber conditions were kept constant throughout the experimental cycle. Seedlings were not grown in one environment and transferred to experimental conditions. Furthermore, plant density was consistent with commercial high tunnel cultivation of baby leafy greens. High-density plant spacing creates light competition, which is missing from studies that use a single plant per pot design.

\section{Materials and Methods}

Growth conditions. This study was completed in two Conviron PGR-15 (Winnipeg, Canada) growth chambers. Air temperature with a set point of $20^{\circ} \mathrm{C} \pm 1{ }^{\circ} \mathrm{C}$ and a 12 -hour photoperiod were constant for both chambers for the duration of the study. The DLI treatment range for this study was based on the recommendations of Glenn et al. (1984) and Runkle (2011), who suggested that a DLI between 8 and $12 \mathrm{~mol} \cdot \mathrm{m}^{-2} \cdot \mathrm{d}^{-1}$ is sufficient for production. Glenn et al. (1984) reported that a minimum DLI of $8 \mathrm{~mol} \cdot \mathrm{m}^{-2} \cdot \mathrm{d}^{-1}$ was required 
to produce market-quality bib lettuce and spinach in an Arizona greenhouse, whereas Runkle (2011) recommended a minimum of $12-14 \mathrm{~mol} \cdot \mathrm{m}^{-2} \cdot \mathrm{d}^{-1}$ for lettuce production. To achieve the various DLI values of $8,10,12$, or $14 \mathrm{~mol} \cdot \mathrm{m}^{-2} \cdot \mathrm{d}^{-1}$ (henceforth referred to as DLI 8, DLI 10, DLI 12, and DLI 14), both growth chambers were programed to deliver photosynthetic photon flux densities (PPFD) of $185,231,278$, and $324 \mu \mathrm{mol} \cdot \mathrm{m}^{-2} \cdot \mathrm{d}^{-1}$ for each 28-d growth cycle. The light source comprised a combination of fluorescent tubes (F39W/T5/841 ECO) and 43-W soft white incandescent bulbs (both lamps from GE, Boston, MA). The chambers featured photosynthetically active radiation $(P A R)$ sensors (model SQ-225; Apogee Instruments, Logan, UT). PPFD levels were checked daily, and adjustments to the light canopy height were performed to maintain $P P F D$ levels $\pm 25 \mu \mathrm{mol} \cdot \mathrm{m}^{-2} \cdot \mathrm{d}^{-1}$ of the desired level. Each DLI level was repeated for a total of four replications.

Plant culture. 'Space' (F1) spinach (Spinacia oleracea), 'Red Russian' kale (Brassica napus pabularia), and 'All Star' lettuce mix (Lactuca sativa) (all from Johnny's Selected Seeds, Winslow, ME) were sown (five rows with $\approx 15$ seeds per row) in galvanized metal flats $(32 \mathrm{~cm} \mathrm{~L} \times 22 \mathrm{~cm} \mathrm{~W} \times 9 \mathrm{~cm}$ D) filled with Sunshine Mix \#1 soilless growing media (Sungro Horticulture, Agawam, MA). Three flats of each species were placed in each of the two growth chambers. Seedlings germinated in 3 to $6 \mathrm{~d}$ after sowing (DAS) and were thinned to 50 seedlings per flat at 7 to 10 DAS $\left(\approx 700\right.$ seedlings $\left./ \mathrm{m}^{2}\right)$, which is the density representative of that used by high tunnel producers of baby leafy greens. Flats were watered as needed and fertilized weekly with a 100-ppm nitrogen solution of 20-20-20 fertilizer (Peters Professional; Scotts, Marysville, $\mathrm{OH})$. Flats were irrigated during the afternoon before data collection so that the leaves were turgid but the leaf surfaces were dry. Data were collected the following morning. Leaf area and chlorophyll were measured, and aboveground biomass was harvested at 28 DAS. The study was conducted between Apr. and Dec. 2018.

Analyses. Leaf area, chlorophyll content, FW, and DW were measured. The first or second true leaf from plants located in the interior of each flat of each species were selected for measurements of the chlorophyll content and leaf area, resulting in a total of six leaves (and, thus, six measurements) for each species in each growth chamber. The average of the six measurements was used for analysis. Because the 'All Star' lettuce mix consisted of four cultivars, a single cultivar (green romaine) was selected for the leaf area and chlorophyll content measurements. The leaf area was determined by obtaining a digital image of each leaf and analyzing the image with Leafscan software (http://www.leafscanapp.com) loaded on an Apple iPhone 6 smart phone (8-megapixel, 1.5-micro pixel iSight camera, aperture f/2.2). The chlorophyll content was estimated using an atLEAF+ chlorophyll meter (FT Green LLC, Wilmington, DE), which compared the transmission of light in red and near-infrared wavelengths to determine the chlorophyll content in green leaves. The atLEAF+ meter produces a unit-less chlorophyll index that is the relative amount of chlorophyll in the tissue with a range of 1 to 100 , and it has been reported to function in a manner similar to that of the more expensive SPAD meter. Zhu et al. (2012) reported $r^{2}$ values of $0.78-0.92$ when comparing atLEAF+ meter readings to SPAD$502 \mathrm{~m}$ readings for five common crop species. Aboveground biomass of the entire flat was clipped and weighed to determine $\mathrm{FW}$; then, it was placed in a drying oven at $40{ }^{\circ} \mathrm{C}$ for $7 \mathrm{~d}$ and weighed again to determine the DW. Fresh and DW for the three trays per species per chamber were averaged to determine the yield observations for each chamber. Average plant fresh and DW were determined by dividing the FW and DW by the number of plants in each tray. An analysis of variance, least significant difference, and linear and quadratic models were performed for the data using $\mathrm{R}$ software version 3.5.1 and RStudio version 1.1456. Species were analyzed separately. Significance was determined at $P<0.05$.

\section{Results}

Influences on $F W$. Lettuce FW increased significantly with a linear trend as DLI increased, ranging from $1.27 \mathrm{~g}$ for DLI 8 to $4.33 \mathrm{~g}$ for DLI $14\left[\mathrm{FW}=-2.8+0.5(\mathrm{DLI}) ; r^{2}=0.82\right]$. Kale and spinach FW were unaffected by the increasing DLI (Table 1).

Influences on $D W$. In contrast to $\mathrm{FW}$, the DW of kale, lettuce, and spinach all showed significant linear increases in response to increasing DLI. These increases implied differences in water content at harvest among the different light intensities, despite consistent irrigation before harvest (Fig. 1). Kale consistently had the highest DW, ranging from $0.188 \mathrm{~g}$ at DLI 8 to $0.277 \mathrm{~g}$ at DLI $14\left[\mathrm{DW}=0.09+0.014(\mathrm{DLI}) ; r^{2}=0.67\right]$, whereas lettuce had the greatest increase in $\mathrm{DW}$, ranging from $0.068 \mathrm{~g}$ at DLI 8 to $0.206 \mathrm{~g}$ at DLI 14 [DW $=-0.12+0.023$ (DLI); $\left.r^{2}=0.85\right]$. Spinach had the lowest rate of increase in DW, ranging from $0.133 \mathrm{~g}$ at
DLI 8 to $0.189 \mathrm{~g}$ at DLI 14 [DW $=0.07+0.008$ (DLI); $\left.r^{2}=0.64\right]$.

Influences on leaf area. In spinach and lettuce, leaf areas were significantly higher at DLI 14 and significantly lower at DLI 8 than with other treatments. Conversely, kale leaf areas were significantly higher at DLI 8 and lower at DLI 14 than with other treatments.

Influences on chlorophyll. The relationship between chlorophyll and DLI for kale was best described by a quadratic model [chlorophyll $=49.3-5.32(\mathrm{DLI})+8.9$ $\left.(\mathrm{DLI})^{2} ; r^{2}=0.34\right]$. Chlorophyll levels decreased from DLI 8 to DLI 12 and then increased at DLI 14. Lettuce and spinach chlorophyll levels displayed similar trends but were not significant at $P<0.05$.

\section{Discussion}

The goals of this study were to advise mid-latitude high tunnel growers regarding how much additional light to provide to maintain the growth of leafy greens throughout low-light winter months and to provide advice regarding which species may be more responsive to additional lighting.

Several studies indicated a positive linear response of FW to increasing light levels (Gent, 2014, 2016; Lefsrud et al., 2006a, 2006b). These studies used a hydroponic growing system that would minimize variations in the tissue water content at harvest. Our study attempted to simulate conditions similar to those of commercial production methods (high plant densities in peat-based growing media). Water content of leafy greens in this study were very high, ranging from $91 \%$ to $95 \%$; therefore, a slight variation in the plant water status at harvest could greatly influence $\mathrm{FW}$ results.

We can conclude that kale, lettuce, and spinach all positively responded to increases in DLI within the relatively narrow range of treatments, but that lettuce benefited the most from increased light: a DLI of 14 resulted in $203 \%$ in DW compared to a DLI of 8 , which resulted in a $47 \%$ increase for kale and a $42 \%$ increase for spinach. We observed DW increases with each additional increase in DLI,

Table 1. Fresh weight, dry weight, leaf area, and chlorophyll (CHL) levels for kale, lettuce, and spinach grown under various daily light integral (DLI) values using fluorescent and incandescent lamps.

\begin{tabular}{|c|c|c|c|c|c|}
\hline Species & DLI $\left(\mathrm{mol} \cdot \mathrm{m}^{-2} \cdot \mathrm{d}^{-1}\right)$ & Fresh wt (g) & Dry wt (g) & Leaf area $\left(\mathrm{cm}^{2}\right)$ & CHL \\
\hline \multirow[t]{4}{*}{ Kale } & 14 & $3.03 \mathrm{a}(0.34)$ & $0.277 \mathrm{a}(0.03)$ & $20.07 \mathrm{ab}(2.28)$ & $49.91 \mathrm{a}$ \\
\hline & 12 & $2.72 \mathrm{a}(0.28)$ & $0.247 \mathrm{ab}(0.00)$ & $18.73 \mathrm{~b}(4.55)$ & $45.60 \mathrm{~b}$ \\
\hline & 10 & $3.33 \mathrm{a}(0.76)$ & $0.236 \mathrm{~b}(0.03)$ & $24.31 \mathrm{ab}(4.88)$ & $48.90 \mathrm{c}$ \\
\hline & 8 & 3.07 a $(0.38)$ & $0.188 \mathrm{c}(0.02)$ & 25.46 a (1.89) & $52.78 \mathrm{~d}$ \\
\hline \multirow[t]{4}{*}{ Lettuce } & 14 & 4.33 a $(0.79)$ & 0.206 a $(0.04)$ & 44.72 a (7.04) & 37.51 \\
\hline & 12 & $2.90 \mathrm{~b}(0.37)$ & $0.146 \mathrm{~b}(0.02)$ & $36.61 \mathrm{ab}(4.90)$ & 34.18 \\
\hline & 10 & $2.39 \mathrm{~b}(0.42)$ & $0.108 \mathrm{~b}(0.02)$ & $33.02 \mathrm{ab}(4.43)$ & 34.95 \\
\hline & 8 & $1.27 \mathrm{c}(0.46)$ & $0.068 \mathrm{c}(0.02)$ & $27.75 \mathrm{~b}(10.13)$ & 38.68 \\
\hline \multirow[t]{4}{*}{ Spinach } & 14 & 2.25 a (0.19) & 0.189 a $(0.01)$ & 14.26 a (1.39) & 45.16 \\
\hline & 12 & $2.07 \mathrm{a}(0.31)$ & $0.166 \mathrm{ab}(0.01)$ & $13.28 \mathrm{ab}(0.38)$ & 41.95 \\
\hline & 10 & $2.20 \mathrm{a}(0.60)$ & $0.152 \mathrm{bc}(0.03)$ & $14.07 \mathrm{a}(1.83)$ & 44.66 \\
\hline & 8 & $2.03 \mathrm{a}(0.14)$ & $0.133 \mathrm{c}(0.01)$ & $11.86 \mathrm{~b}(1.23)$ & 46.48 \\
\hline
\end{tabular}

Standard errors are reported within the parentheses. Species were analyzed separately. Lowercase letters refer to significant differences $(P<0.05$ level) between DLI levels determined by the least significant difference test. Quadratic models were fit for the CHL levels. Letters refer to significant difference at $P<$ 0.05 . 


\section{A. Kale Dry Mass}

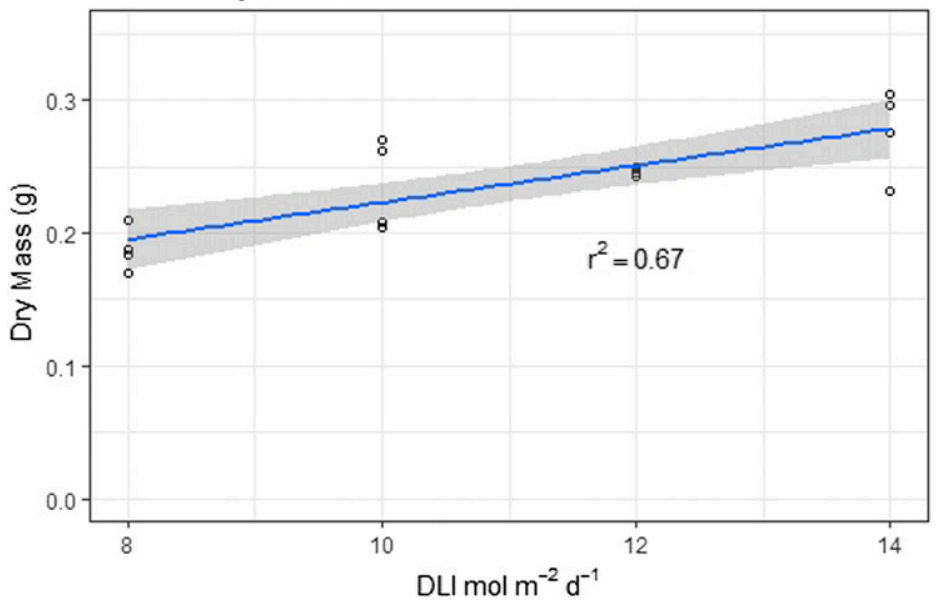

B. Lettuce Dry Mass

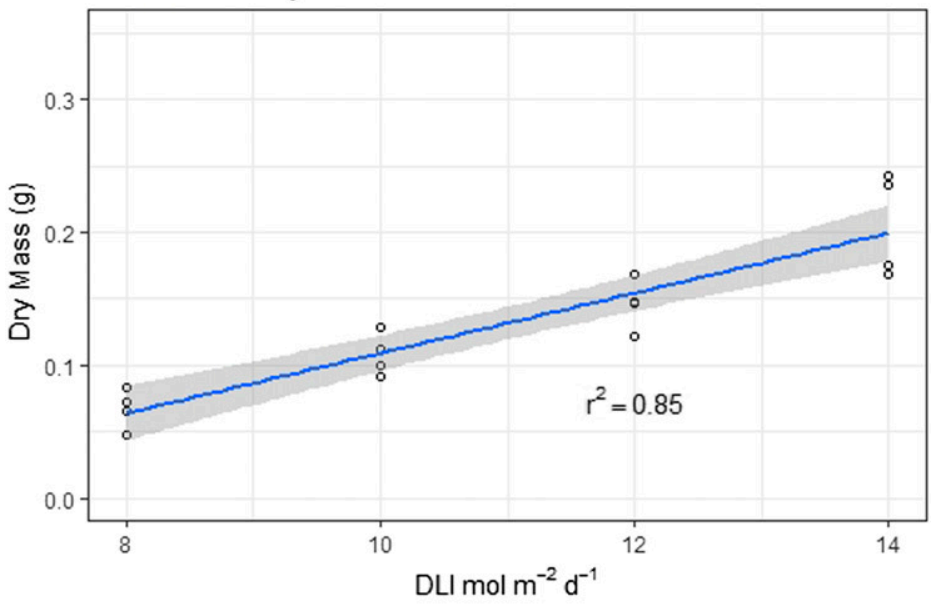

C. Spinach Dry Mass

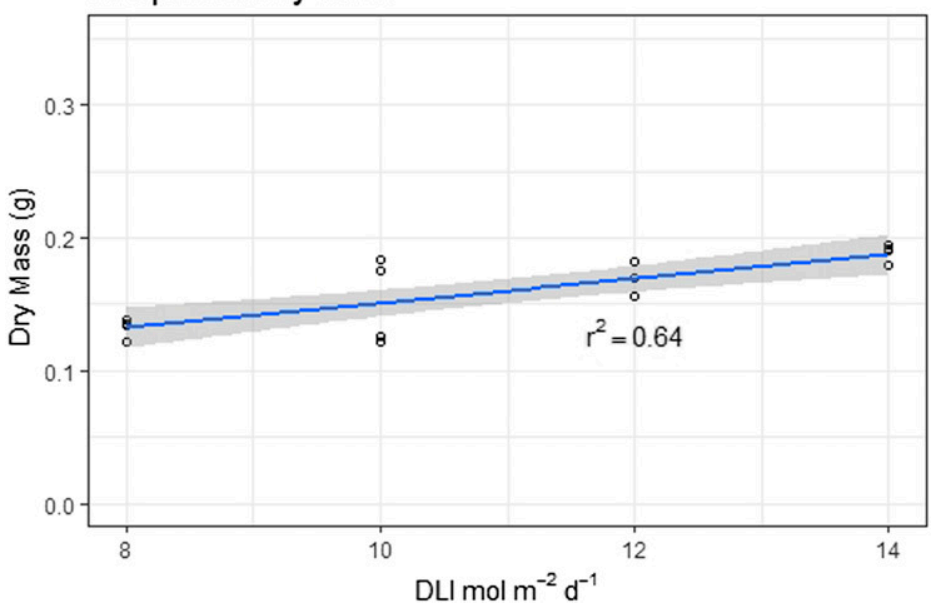

Fig. 1. Average dry weight per plant of kale (A), lettuce $(\mathbf{B})$, and spinach $(\mathbf{C})$ at a daily light integral (DLI) of $8,10,12$, and $14 \mathrm{~mol} \cdot \mathrm{m}^{-2} \cdot \mathrm{d}^{-1}$. Shading around the lines depicts the $95 \%$ confidence interval.

but increases between DLI 10 and DLI 12 treatments were always insignificant, indicating that the addition of $2 \mathrm{~mol} \cdot \mathrm{m}^{-2} \cdot \mathrm{d}^{-1}$ to increase the DLI from 10 to 12 was not effective. However, DW increases for lettuce between DLI 12 and DLI 14 were significant, indicating that a $2 \mathrm{~mol} \cdot \mathrm{m}^{-2} \cdot \mathrm{d}^{-1}$ addition could be effective for lettuce at a DLI of $12 \mathrm{~mol} \cdot \mathrm{m}^{-2} \cdot \mathrm{d}^{-1}$. The increases in DW corresponded with larger leaf areas for lettuce and spinach. Curiously, kale had less leaf area at a higher DLI $\left(18.73 \mathrm{~cm}^{2}\right.$ at DLI 12) and higher leaf area at a lower DLI $\left(25.46 \mathrm{~cm}^{2}\right.$ at DLI 8). Leaves may develop larger but thinner, which is a species-specific mechanism to intercept more light in low-light conditions.
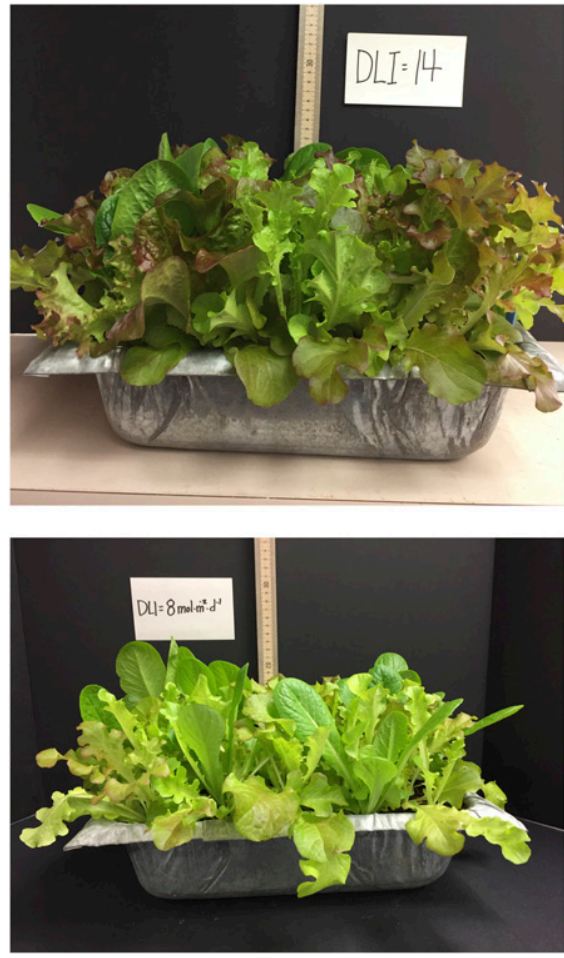

Fig. 2. Leaf color influenced by daily light integral (DLI). All Star lettuce mix grown for $28 \mathrm{~d}$ in a growth chamber at DLI of $14 \mathrm{~mol} \cdot \mathrm{m}^{-2} \cdot \mathrm{d}^{-1}$ (top) and DLI of $8 \mathrm{~mol} \cdot \mathrm{m}^{-2} \cdot \mathrm{d}^{-1}$ (bottom).

We observed a consistent trend whereby chlorophyll levels decreased from DLI 8 to DLI 12 and then increased from DLI 12 to DLI 14, indicating a similar reaction to increasing light levels across cultivars. Low-light conditions affect the density and size of chloroplasts. Fu et al. (2012) found fewer chloroplasts in lettuce grown under lowlight conditions than in lettuce grown under high-light conditions, but they also found that low-light chloroplasts covered more surface area. Furthermore, research suggested that the chloroplasts themselves are denser in plants grown in lowlight conditions than those grown in higher-light conditions. Lichtenthaler et al. (1982) found broader grana and higher grana stacks with more thylakoids per granum in radish seedlings grown in lowlight conditions than in those grown in higherlight conditions. This combination of denser, wider chloroplasts leads to higher pigment density (Lichtenthaler et al., 1982). Our study indicated that chlorophyll levels in plants grown under low to moderate DLI levels are species-dependent and require further investigation.

Although not quantitatively measured, red pigment expression in the red oak leaf lettuce cultivar included in the All Star mix was greatly influenced by DLI. Leaves had little to no red coloration at DLI 8 and moderate red pigment expression at DLI 14 (Fig. 2). This observation was consistent with that of reports in the literature that correlated low light with reduced anthocyanin production (Kleinhenz et al., 2003). 
Practical application for northern high tunnel growers. Faust and Logan's interactive DLI map indicated that the monthly average DLI in Bozeman, MT for November is $11.3 \mathrm{~mol} \cdot \mathrm{m}^{-2} \cdot \mathrm{d}^{-1}$. A typical high tunnel covered with a single layer of greenhouse plastic film located in Bozeman, Montana, blocks $\approx 35 \%$ of the incoming PAR in early November (Baumbauer, 2019). This reduction resulted in a DLI of $\approx 7 \mathrm{~mol} \cdot \mathrm{m}^{-2} \cdot \mathrm{d}^{-1}$ within the high tunnel. Using this information, high tunnel growers can calculate locally specific additional light requirements for each cultivar and allocate additional lighting toward cultivars that respond more to a given DLI increase.

\section{Literature Cited}

Baumbauer, D.A. 2019. Extending cool season production of vegetables in the high tunnel: Balancing heat and light. Mont. State Univ., Bozeman, PhD Diss.

Biernbaum, J.A. 2013. Hoophouses and high tunnels for local food and farming. 10 Oct. 2018. <https:// www.canr.msu.edu/hrt/uploads/535/78622/ HightunnelHoophouseSolarGreenhouse201321 pgs.pdf $>$.

Bumgarner, N.R., M.A. Bennett, P.P. Ling, R.W Mullen, and M.D. Kleinhenz. 2012. Active and passive zonal heating creates distinct microclimates and influences spring and fall time lettuce growth in Ohio. HortTechnology 22:228-236.

Coleman, E. 2009. The winter harvest handbook: Year-round vegetable production using deeporganic techniques and unheated greenhouses. Chelsea Green Publishing, White River Junction, VT.

Drost, D., T. Ernst, and B. Black. 2017. Soil heating and secondary plant covers influence growth and yield of winter high tunnel spinach. HortScience 52:1251-1258.
Faust, J.E. and J. Logan. 2018. Daily light integral: A research review and high-resolution maps of the United States. HortScience 53:1250-1257.

Fu, W., P. Li, and Y. Wu. 2012. Effects of different light intensities on chlorophyll fluorescence characteristics and yield in lettuce. Scientia Hort. 135:45-51.

Fu, Y., H. Li, J. Yu, H. Liu, Z. Cao, N. Manukousky, and H. Liu. 2017. Interaction effects of light intensity and nitrogen concentration on growth, photosynthetic characteristics and quality of lettuce (Lactuca sativa L. var. youmaicai). Scientia Hort. 214:51-57.

Gaudreau, L., J. Charbonneau, L-P. Vézina, and A. Gosselin. 1994. Photoperiod and photosynthetic photon flux influence growth and quality of greenhouse-grown lettuce. HortScience 29:1285-1289.

Gent, M.P. 2014. Effect of daily light integral on composition of hydroponic lettuce. HortScience 49:173-179.

Gent, M.P. 2016. Effect of irradiance and temperature on composition of spinach. HortScience 51:133-140.

Glenn, E.P., P. Cardran, and T.L. Thompson. 1984. Seasonal effects of shading on growth of greenhouse lettuce and spinach. Scientia Hort. 24:231-239.

Hunter, B., D. Drost, B. Black, and R. Ward. 2012. Improving growth and productivity of earlyseason high tunnel tomatoes with targeted temperature additions. HortScience 47:733-740.

Kleinhenz, M.D., A. Gazula, J.C. Scheerens, and D.G. French. 2003. Variety, shading, and growth stage effects on pigment concentrations in lettuce grown under contrasting temperature regimens. HortTechnology 13:677-683.

Kopsell, D.A., D.E. Kopsell, M.G. Lefsrud, J. CurranCelentano, and L.E. Dukach. 2004. Variation in lutein, $\beta$-carotene, and chlorophyll concentrations among Brassica oleracea cultigens and seasons. HortScience 39:361-364.

Lefsrud, M.G., D.A. Kopsell, R.M. Augé, and A. Both. 2006a. Biomass production and pigment accumulation in kale grown under increasing photoperiods. HortScience 41:603-606.

Lefsrud, M.G., D.A. Kopsell, D.E. Kopsell, and J. Curran-Celentano. 2006b. Irradiance levels affect growth parameters and carotenoid pigments in kale and spinach grown in a controlled environment. Physiol. Plant. 127:624-631.

Lichtenthaler, H., G. Kuhn, U. Prenzel, C. Buschmann, and D. Meier. 1982. Adaptation of chloroplast-ultrastructure and of chlorophyllprotein levels to high-light and low-light growth conditions. Z. Naturforsch. 37:464475.

Nelson, P.V. 2012. Greenhouse operation and management. Pearson Prentice Hall, Upper Saddle River, NJ.

Proietti, S., S. Moscatello, G. Colla, and Y. Battistelli. 2004. The effect of growing spinach (Spinacia oleracea L.) at two light intensities on the amounts of oxalate, ascorbate and nitrate in their leaves. J. Hort. Sci. Biotechnol. 79:606-609.

Runkle, E. 2011. Lighting greenhouse vegetables. Greenhouse Product News 12:42.

Steidle Neto, A.J., L. Morua, D. Lopes, L. Carlos, L. Martins, and L. Ferraz. 2017. Nondestructive prediction of pigment content in lettuce based on visible-NIR spectroscopy. J. Sci. Food Agr. 97:2015-2022.

Yao, X.Y., X.Y. Liu, Z.G. Xu, and X.L. Jiao. 2017. Effects of light intensity on leaf microstructure and growth of rape seedlings cultivated under a combination of red and blue LEDs. J. Integr. Agr. 16:97-105.

Zhu, H., X. Li, W. Zhai, Q. Gao, J. Liu, L. Ren, H. Chen, and Y. Zhy. 2017. Effects of low light on photosynthetic properties, antioxidant enzyme activity, and anthocyanin accumulation in purple pak-choi (Brassica campestris ssp. Chinensis Makino). PLoS One 12:e179305.

Zhu, J., N. Tremblay, and Y. Liang. 2012. Comparing SPAD and atLEAF values for chlorophyll assessment in crop species. Can. J. Soil Sci. 92:645-648. 